Brazilian Journal

of Chemical

Engineering

\title{
ESTIMATION OF PARAMETERS AND STATES USING A BAYESIAN PARTICLE FILTER FOR THE SULFATE ION ADSORPTION PROCESS IN A FIXED BED COLUMN
}

\author{
Rhynara N. S. de Carvalho' ${ }^{1}$, Damaris Guimarães ${ }^{1}$, Versiane A. Leão², \\ Julio C. S. Dutra ${ }^{1}$ and Wellington B. da Silva ${ }^{1 *}$ \\ ${ }^{1}$ Universidade Federal do Espírito Santo, Departamento de Engenharia Rural, Alegre, ES, Brasil. ORCID: 0000-0001-7234-1881; \\ ORCID: 0000-0002-4932-3252; ORCID: 0000-0001-6784-4150; E-mail: wellingtonufes@gmail.com - ORCID: 0000-0003-2242-7825 \\ 2 Universidade Federal de Ouro Preto, Departamento de Engenharia Metalúrgica e de Materiais, Ouro Preto, MG, Brasil. \\ ORCID: 0000-0001-9495-6529
}

(Submitted: February 8, 2018 ; Revised: November 7, 2018 ; Accepted: February 7, 2019)

\begin{abstract}
Ensuring that industrial effluents meet quality standards to be released into water bodies is still one of the major environmental concerns. Liquid phase adsoption in fixed bed collumns is one of the most known treatments. Measurements are needed to monitor the process. However, as they are often corrupted by noise from the measuring equipment, performing an accurate analysis becomes an important challenge. The present work demonstrates the effectiveness of particle filter Sampling Importance Resampling as a fast and robust tool for monitoring a problem of sulfate ion removal. Experimental measurements were used to validate the methodology and the particle filter (PF) performance was evaluated by means of error metrics, computational time and compared to the Unscented Kalman Filter. The results show that the PF provides sequentially very accurate estimates for the sulfate adsorption breakthrough curve.

Keywords: State estimation; Particle filter; Modeling; Adsorption; Fixed bed.
\end{abstract}

\section{INTRODUCTION}

The pollution rate of water resources presents a major problem in nature, because the release of numerous chemical compounds affects the water cycle. This issue is mainly due to economic and population growth (Sajid et al., 2017). Among pollutants, sulfate $\left(\mathrm{SO}_{4}{ }^{2-}\right)$ is a common ion in natural waters and may be present in high concentrations in industrial effluents such as wastewater from mining, metallurgy, textiles, landfills and fertilizers (Dou et al., 2017). The highly soluble characteristic makes the removal of sulfate from water more difficult and consequently more costly. In addition, it may cause the appearance of odors, interference in the natural sulfur cycle, and cathartic effects and dehydration in human health at concentrations above $500 \mathrm{mg} / \mathrm{L}$ (WHO, 2008; Tait et al., 2009).

In this context, the search for effective treatments provides alternatives to the minimization of discharges of such pollutants, avoiding damage to health and the ecosystem (Abdulgader et al., 2013). Among the various technologies for the treatment of industrial effluents, adsorption and ion-exchange processes in fixed-bed columns stand out. These processes present advantages, such as an average operational cost and high efficiency, when compared to other techniques of membrane separation and electrodialysis (Haghsheno et al., 2009; Bhatnagar and Sillanpää, 2011).

However, it is known that measurements, generally taken at the outlet of an adsorption column, are corrupted by noise characteristic of the measuring

\footnotetext{
*Corresponding author: Wellington B. da Silva - E-mail: wellingtonufes@gmail.com
} 
instruments (Khatibisepehr et al., 2013; Zhou et al., 2017). Therefore, a satisfactory monitoring tool requires methods that are able to provide a more accurate analysis of the process. As a result, it is possible to describe the behavior of the adsorption, also known as the breakthrough curve (Shao et al., 2010). For this reason, the use of mathematical models combined with estimation tools may be considered as a great strategy to perform process monitoring (Khatibisepehr et al., 2013; Zhou et al., 2017). With more reliable values, one can perform process analysis, unmeasured variable and parameter inference, and improve the input data to feedback controllers.

In a wider sense, optimization methods have been used in the estimation of parameters and the adsorption breakthrough curve, such as a particle swarm optimization algorithm in the studies of Burkert et al. (2011) and, more recently, genetic algorithms used by Emigdio et al. (2017) to construct the breakthrough curve of phenol adsorption on activated carbon. However, such optimization methods may face convergence problems, require more computational time and consequently have delayed responses, which would become impractical.

When the objective is online monitoring, it is interesting to apply Bayesian methods, which seek to approximate sequentially the posterior density function (PDF) of the desired variables from the measured data (Doucet et al., 2001). Therefore, it is possible to reduce uncertainties in measurements and to perform inference of the parameters and latent variables.

In this context, the Kalman Filter (KF) is the bestknown estimation tool, with applicability in systems that use the adsorption of gaseous compounds through pressure. Some examples are found in the works of Won and Lee (2012) and Fakhroleslam et al. (2016). However, the application of the KF is limited to Gaussian and linear (or linearized) systems. Even the extended (EKF) and unscented (UKF) versions, which can be applied to locally linearized and nonlinear problems, respectively, may not be suitable due to the complex process behavior and plant-model mismatch. An alternative to deal with such problems is the use of so-called Sequential Monte Carlo methods, also known as particle filters (PFs) (Doucet et al., 2000), which can be applied to a large class of systems.

PFs have received attention since the early 2000s to approximate estimation problems (Doucet et al., 2000; Arulampalam et al., 2002; Chen et al., 2008; Shao et al., 2010; Khatibisepehr et al., 2013). For example, Shenoy et al. (2013) compared the EKF, UKF and PF for polymerization processes, which are highly nonlinear systems, and observed that PFs delivered more accurate estimates. The main reason is that the PF algorithms are indicated for nonlinear and non-Gaussian systems, as is the case of industrial applications (Chen et al., 2008).
The efficiency of such algorithms has been shown by several authors in the area of heat conduction (Orlande et al., 2008; Vianna et al., 2013; Silva et al., 2016), of polymerization processes (Shenoy et al., 2011; Shenoy et al., 2013) and in the realization of predictions of the life of lithium-ion batteries (Walker et al., 2015). Recently, Dias et al. (2017) proposed a virtual sensor comprising a PF algorithm for state estimation and an artificial neural network (ANN) to predict the final quality of the product obtained in a polymerization reactor.

The PF algorithms may demand high processing time when compared to the family of KFs. However, this problem can be overcome (or at least alleviated) if proper technology is deployed, such as parallel computing to accelerate the calculation (Lopez et al., 2014; Schwiegelshohn et al., 2016). Lopez et al. (2015) found that the CPU time of the PF was "two orders of magnitude faster than the physical process even for calculations that involve millions of particles". More recently, Stelzer et al. (2017) showed that the $\mathrm{PF}$ can provide accurate estimation in real-time state estimation. For a batch-fed bioprocess, they found that 5000 particles took about 2.5 min of CPU time. Thus, the reader concerned about the online application, especially when the model complexity must be retained, can rely on new computing technologies, which are daily becoming faster with the advent of the Internet of Things (IoT) (Harjunkoski, 2017).

The fixed-bed adsorption process distributed problem is very common in engineering systems, such as flow through pipe-in-pipe lines, wildfire spread, natural heat convection, heat transfer in bio-systems, solidification front in phase change problems, and so on (Orlande et al, 2012; Silva et al, 2014; Marques et al., 2014). Despite the wide use of PF algorithms in distributed problems, to the best knowledge of the authors they have not yet been applied to fixed-bed adsorption processes. Specifically, there are no works dealing with the mathematical modeling and estimation of sulfate adsorption in ion-exchange columns.

To fill this gap, the present work proposes the use of a Bayesian approach with a PF in order to perform a more accurate analysis of the adsorption behavior over time. Specifically, this filter can be used for parameter estimation and real-time monitoring of latent states, as well as for reducing random measurement errors. Therefore, the technique proposed here is attractive in the context of adsorption processes, since nonlinear behavior and uncertainties from measuring devices are inherent in such applications.

In this work, the tasks of the PF (uncertainty reduction and observation of latent variables) are performed with the available measured data from Guimarães and Leão (2014a) and the dynamic system model. In this regard, the real measurements of sulfate concentration obtained at the outlet of the adsorption 
column are to be filtered. At the same time, it is possible to observe the complete sulfate concentration profile along the column and also to estimate parameters related to the flow rate.

In the following section, a background of the adsorption process modeling is presented for simulation and monitoring purposes, followed by a presentation of the Bayesian approach for parameters and state estimation, describing briefly the fundamental principles and a particular algorithm: Sequential Importance Resampling (SIR). In the sequence, the necessary steps to implement the proposed estimation scheme are described, regarding the real data, the model formulation and the SIR algorithm. Then, the performance of the proposal is discussed in the results. Finally, the paper is concluded with the main conclusions obtained in the study.

\section{MATHEMATICAL MODELING OF THE ADSORPTION PROCESS}

The mathematical model of the adsorption process in a fixed-bed column is used to predict the concentration profile over time and space for any changes defined in the initial and boundary conditions, such as feed concentration, temperature and flow rate. So, it is paramount to develop a first-principles model, considering relevant transport phenomena. The numerical simulation of such a model allows a better understanding of the behavior during the adsorption cycles and prediction of the breakthrough curve (Shafeeyan et al., 2013).

Since the data used in this manuscript were obtained through experiments carried out at $25{ }^{\circ} \mathrm{C}$ and there were no feed-temperature disturbances and no heat exchanger around the column (Guimarães and Leão, $2014 \mathrm{a}, 2014 \mathrm{~b}$ ), the process is isothermal. Besides that, the pressure drop was also neglected, mainly due to the small size of the column $(0.09 \mathrm{~m})$ and to the relatively large particles $(770 \mu \mathrm{m})$. Thus, the mass balance was used to model the liquid-phase adsorption over the fixed bed. According to Equation 1, this model is characterized by only two independent variables, time (t) and column length (z) (Ruthven, 1984; Chu, 2010).

$\frac{\partial \mathrm{C}}{\partial \mathrm{t}}=\mathrm{D}_{\mathrm{L}} \frac{\partial^{2} \mathrm{C}}{\partial \mathrm{z}^{2}}-\mathrm{u}_{0} \frac{\partial \mathrm{C}}{\partial \mathrm{z}}-\left(\frac{1-\varepsilon}{\varepsilon}\right) \rho_{\mathrm{L}} \frac{\partial \mathrm{q}}{\partial \mathrm{t}}$

In this representation, $\mathrm{u}_{0}$ is the interstitial velocity of the fluid phase in the column, $\mathrm{C}$ is the adsorbate concentration of the liquid phase, $\varepsilon$ is the bed porosity, $\rho_{\mathrm{L}}$ is the adsorbent density, $\mathrm{q}$ is the average adsorbate concentration in the adsorbent and $\mathrm{D}_{\mathrm{L}}$ is the axial dispersion coefficient (Chu, 2010).

To solve this model, besides the initial and boundary conditions it is necessary to use a mass transfer rate expression $\partial \mathrm{q} / \partial \mathrm{t}$. In the literature, the Thomas' and the Bohart-Adams' models (Chu, 2010; Guzman et al., 2016; Dong and Lin, 2017) and the Linear Driving Force (LDF) model have been employed in several studies involving fixed-bed adsorption (Barros et al., 2004; Otero et al., 2005; Souza et al., 2008).

However, such models consider different modelling assumptions. For instance, the Thomas' and the Bohart-Adams' models disregard intraparticle diffusion, resistance to external mass transfer and axial dispersion (Chu, 2010; Guzman et al., 2016). The wide applicability of these models is due to the ease of linearization to obtain analytically the curves representing the adsorption behavior (Asku and Gönen, 2004; Dong and Lin, 2017). On the other hand, the LDF model considers the resistance to diffusion in the liquid film as the controlling stage and that axial dispersion is important.

Since the LDF model describes better the characteristics of the flow and provides results closer to reality (Ruthven, 1984), the term $\partial \mathrm{q} / \partial \mathrm{t}$ can be represented by Equation 2. In this expression, the parameter $\mathrm{k}_{\mathrm{e}}$ is the mass transfer coefficient in the liquid film external to the particle, $a_{v}$ is the surface area of the adsorbent particle, and $\mathrm{C}_{\mathrm{eq}}$ is the equilibrium concentration in the liquid phase.

$\frac{\partial \mathrm{q}}{\partial \mathrm{t}}=\mathrm{k}_{\mathrm{e}} \mathrm{a}_{\mathrm{v}}\left(\mathrm{C}-\mathrm{C}_{\mathrm{eq}}\right)$

\section{STATE AND PARAMETER ESTIMATION USING THE PF}

In some problems in engineering, it is not possible to measure directly all variables in the process. Thus, it becomes attractive to perform measurements of other variables and to obtain sequentially information of the unobserved variable (latent variables) through the mathematical model of the process. This indirect measurement of the variable of interest is called a state estimate (Shao et al., 2010).

Within the Bayesian framework, the dynamic problem is regarded as a Markovian process, using an evolution and an observation model as given by Equations $3 \mathrm{a}$ and $3 \mathrm{~b}$, respectively (Chen et al., 2005; Arulampalam et al., 2002; Ristic et al., 2004):

$$
\begin{aligned}
& \mathrm{x}_{\mathrm{k}}=\mathrm{f}\left(\mathrm{x}_{\mathrm{k}-1}, \mathrm{v}_{\mathrm{k}}\right) \\
& \mathrm{z}_{\mathrm{k}}=\mathrm{h}\left(\mathrm{x}_{\mathrm{k}}, \mathrm{n}_{\mathrm{k}}\right)
\end{aligned}
$$

In this representation, $\mathrm{f}$ is the nonlinear model of the dynamical problem accounting for the state vector $\mathrm{x}_{\mathrm{k}} \in \mathrm{R}^{\mathrm{n}}$ and the uncertainty $\mathrm{v}_{\mathrm{k}} \in \mathrm{R}^{\mathrm{n}}$. The state vector contains the variables to be dynamically estimated at 
each sampling time instant $k$. The function $\mathrm{h}$ is possibly nonlinear and describes the dependence between the measurements $\mathrm{z}_{\mathrm{k}} \in \mathrm{R}^{\mathrm{nz}}$ and the updated state variables and the uncertainty $n_{k} \in R^{n z}$.

The approach to the problem by using a PF considers the estimation of the latent states from the observed or measured variables, so that after each sequential observation the state that gives rise to this observation is estimated (Arulampalam et al., 2002). Therefore, the set of particles generated by the algorithm becomes the possible representation of the state (Speekenbrink, 2016).

For the measured data $\mathrm{z}_{\mathrm{k}}^{\text {obs }}$ at the time instant $\mathrm{k}, \mathrm{N}_{\mathrm{p}}$ particles for the states,

$\left\{\mathrm{x}_{\mathrm{k}-1}^{(\mathrm{i})}\right\}_{\mathrm{i}=1}^{\mathrm{N}_{\mathrm{p}}}$

are drawn from a prior PDF. Such particles are propagated using the state evolution model and updated with the observation model in order to give the measurement estimates,

$\left\{z_{k}^{(i)}\right\}_{i=1}^{N_{p}}$

Afterwards, a likelihood function assigns an importance weight,

$\mathrm{w}_{\mathrm{k}}^{(\mathrm{i})} \propto \pi\left(\mathrm{z}_{\mathrm{k}}^{(\mathrm{i})} \mid \mathrm{z}_{\mathrm{k}}^{\mathrm{obs}}\right)$.

The set of the updated states and the weights,

$\left\{\mathrm{x}_{\mathrm{k}}^{(\mathrm{i})}, \mathrm{w}_{\mathrm{k}}^{(\mathrm{i})}\right\}_{\mathrm{i}=1}^{\mathrm{N}_{\mathrm{p}}}$,

represents the approximation for the PDF.

A problem that may arise is the degeneracy phenomenon, which can be avoided with the particle resampling performed by the Sequential Importance Resampling (SIR) algorithm. The objective of this step is to replicate the particles with larger or more important weights (close to 1) and to eliminate those with smaller weights that have little effect on the estimates. For further details about the PFs, the reader is referred to Chen et al. (2005), Arulampalam et al. (2002), and Chatzi and Smyth (2009).

\section{MATERIALS AND METHODS}

The PF is used in this work to reduce measurement uncertainties and to allow monitoring of an adsorption column. According to Figure 1, from the initial data such as concentration $\left(\mathrm{C}_{0}\right)$ and flow rate $\left(\mathrm{Q}_{0}\right)$, the measurements of the effluent sulfate concentration

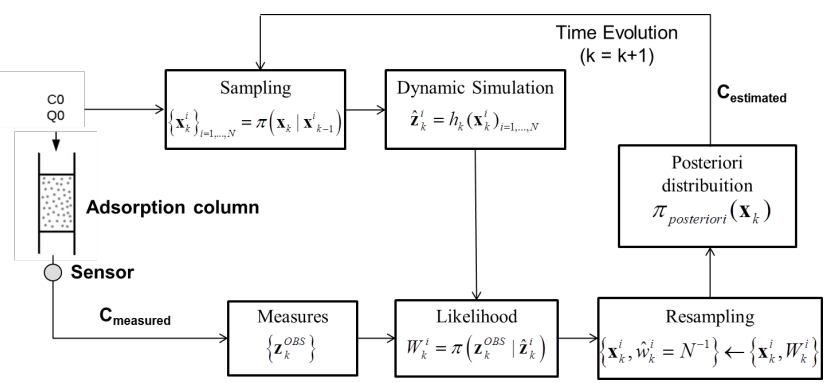

Figure 1. Schematic representation of the monitoring of the adsorption column.

$\left(\mathrm{C}_{\text {measured }}\right)$ are obtained by a sensor at the column outlet, and comprise the observation vector $\left(\mathrm{z}_{\mathrm{k}}\right.$ obs $)$.

The initial data are used as a priori knowledge to draw the particles represented as

$\left\{x_{k}^{i}\right\}_{i=1, \ldots, N}$,

which are updated through dynamic simulation to give

$\left\{\hat{\mathrm{z}}_{\mathrm{k}}^{\mathrm{i}}\right\}_{\mathrm{i}=1, \ldots, \mathrm{N}}$.

These estimates are compared with the measurements by means of the likelihood function, which assigns weights $\left(\mathrm{w}_{\mathrm{k}}{ }^{\mathrm{i}}\right)$ to the particles in order to perform the resampling and to estimate the states from the $a$ posteriori distribution. Consequently, the estimation tool provides the estimated concentration of sulfate $\left(C_{\text {estimated }}\right)$, not only at the outlet but the profile along the column. This procedure is carried out over time for each $C_{\text {measured }}$ from the measuring device using the concentration profile estimated for the previous time.

\section{Obtaining the measurements}

Aiming at removing sulfates from industrial waters, Guimarães and Leão (2014a, 2014b) carried out an experimental study of the adsorption of $\mathrm{SO}_{4}^{2-}$ at constant temperature in a fixed bed composed of Purolite A500 resin. Their data were used as information in the process models and in the PF. In addition, the concentration measurements obtained at the outlet of the column were considered as the observation $\mathrm{z}_{\mathrm{k}}^{\text {obs }}$. Thus, it is possible to investigate the behavior of the adsorption and to reduce the uncertainties in the experimental data. The operational data are shown in Table 1.

\section{Formulation required for the mathematical model}

The models shown in Equations 1 and 2 were used to study the adsorption in this work. The LDF was proposed to model the mass transfer due to the satisfactory data fitting obtained by Guimarães and Leão (2014a) in the adsorption kinetics test. They showed that the pseudo-first-order model fits better the data obtained in the batch experiment of $\mathrm{SO}_{4}^{2-}$ 
Table 1. Operating parameters of the column and the process.

\begin{tabular}{lcc}
\hline \multicolumn{1}{c}{ Parameter } & Value & Unit \\
\hline Cross sectional area of column $(\mathrm{S})$ & 0.000531 & $\mathrm{~m}^{2}$ \\
Bed height $(\mathrm{L})$ & 0.09 & $\mathrm{~m}$ \\
Porosity of bed $(\varepsilon)$ & 0.35 & - \\
Particle diameter $\left(\mathrm{d}_{\mathrm{p}}\right)$ & 0.00077 & $\mathrm{~m}$ \\
Particle radius $\left(\mathrm{r}_{\mathrm{p}}\right)$ & 0.000385 & $\mathrm{~m}$ \\
Density of liquid $\left(\rho_{\mathrm{L}}\right)$ & $1 \cdot 10^{3}$ & $\mathrm{~kg} / \mathrm{m}^{3}$ \\
Density of the bed $\left(\rho_{\mathrm{s}}\right)$ & $1.134 \cdot 10^{3}$ & $\mathrm{~kg} / \mathrm{m}^{3}$ \\
Viscosity of the mixture $\left(\mu_{\mathrm{m}}\right)$ & $53.49 \cdot 10^{-3}$ & $\mathrm{~kg} /(\mathrm{m} \cdot \mathrm{min})$ \\
Initial concentration $\left(\mathrm{C}_{0}\right)$ & 170 & $\mathrm{mg} / \mathrm{m}^{3}$ \\
\hline
\end{tabular}

adsorption, meaning that the diffusion mechanism is controlled by resistance to mass transfer to the outer film of the particle. To solve the model, the constitutive equations arranged in Table 2 were used.

In addition, it was necessary to determine the equilibrium concentration $\mathrm{C}_{\mathrm{eq}}$ in the liquid phase used in the LDF model. The batch data from Guimarães and Leão (2014a) were adjusted using MATLAB software to the Langmuir model given in Equation 4, which assumes monolayer adsorption on an ideal surface $(\mathrm{Wu}$ et al., 2013). In this isotherm, $\mathrm{q}_{\mathrm{eq}}$ is the resin loading at equilibrium, $\mathrm{C}_{\mathrm{eq}}$ is the equilibrium concentration of the adsorbate in solution, $\mathrm{q}_{\max }$ is the maximum loading, and $b$ is a constant related to the affinity between the resin and the adsorbate.

$\mathrm{q}_{\mathrm{eq}}=\mathrm{q}_{\max }\left(\frac{\mathrm{C}_{\mathrm{eq}}}{1+\mathrm{bC}_{\mathrm{eq}}}\right)$

Different isotherms could be chosen to find the parameter $\mathrm{C}_{\mathrm{eq}}$. However, in our studies, it was found that, although some isotherms fit better the experimental data, such a choice does not have a significant effect on the quality of the estimates, mainly due to the presence of noise in the measurements.

\section{Model scaling and dynamic simulation}

In this section, model scaling was carried out with the aim of simplifying the physical problem and guaranteeing dimensional homogeneity according to the expressions $\tau=\left(\mathrm{t} . \mathrm{u}_{0}\right) / \mathrm{L}, \mathrm{x}=\mathrm{Z} / \mathrm{L}$, and $\mathrm{Pe}=\left(\mathrm{L} \cdot \mathrm{u}_{0}\right) /$ $\mathrm{D}_{\mathrm{L}}$, in such a way as to give a nondimensional model.
Thus, the modified model resulted in the equations shown in Table 3. In addition, mathematical expressions required for the model are given in Table 4.

The method of lines was applied for the numerical solution of the model, whose spatial derivatives were approximated by finite differences in order to obtain a set of ordinary differential equations (ODEs). The resulting equations can be solved numerically by a computational algorithm (Berardi and Vurro, 2015) such as ode15s in MATLAB. This method was chosen due to the simplicity of the explicit method and the advantage of stability (Shakeri and Dehghan, 2008).

It was necessary to perform a grid convergence analysis in order to define the number of points for the finite approximation of the spatial derivatives. Different numbers of discretization points were investigated along the axial direction of the column. To select a suitable grid, the relative simulation error (SErr) was considered according to Equation 5, which takes into account different values of the simulated concentration $\mathrm{C}_{\mathrm{N}}(\tau, \mathrm{x})$ according to the number of discretization points $(\mathrm{N})$, the dimensionless time instants $(\tau)$ and the axial position in the column (x). This error is calculated taking the grid with the highest degree of refinement (Nmax) as the reference.

$$
\operatorname{Serr}(\tau, \mathrm{x}, \mathrm{N})=\left|\mathrm{C}_{\mathrm{N} \max }(\tau, \mathrm{x})-\mathrm{C}_{\mathrm{N}}(\tau, \mathrm{x})\right| / \mathrm{C}_{\mathrm{N} \max }(\tau, \mathrm{x})
$$

To assure the grid convergence, the threshold of $\max ($ SErr $) \leq 5 \%$ should be satisfied. This error was observed in two different positions: in the central position $(\mathrm{x}=0.5)$ and at the end of the column $(\mathrm{x}$ $=1.0)$; and at three dimensionless time instants $(\tau)$ : $0.7174,1.5245$ and 2.3316. Such positions and time instants were selected throughout the simulations,

Table 3. Nondimensional mathematical model of the adsorption column.

\begin{tabular}{lc}
\hline \multicolumn{1}{c}{ Description } & Equations \\
\hline Adsorption column model & $\frac{\partial \mathrm{C}}{\partial \tau}=\frac{1}{\mathrm{Pe}} \frac{\partial^{2} \mathrm{C}}{\partial \mathrm{x}^{2}}-\frac{\partial \mathrm{C}}{\partial \mathrm{x}}-\rho_{\mathrm{L}} \frac{1}{\varepsilon} \frac{\partial \mathrm{q}}{\partial \tau}$ \\
Initial condition & $\mathrm{C}(0, \mathrm{x})=0$ \\
Boundary conditions & $\frac{\partial \mathrm{C}}{\partial \mathrm{x}}=\mathrm{Pe}\left[\mathrm{C}(\tau, 0)-\mathrm{C}_{0}\right]$ at $\mathrm{x}=0$ \\
& $\frac{\partial \mathrm{C}}{\partial \mathrm{x}}=0$ at $\mathrm{x}=1$ \\
\hline
\end{tabular}

Table 2. Mathematical formulations of the LDF model.

\begin{tabular}{lcc}
\hline \multicolumn{1}{c}{ Name } & Model & Reference \\
\hline External surface area per unit particle volume (av) & $\mathrm{a}_{\mathrm{v}}=\frac{3}{\mathrm{r}_{\mathrm{p}}}$ & Ruthven (1984) \\
Coefficient of mass transfer in the external liquid film $\left(\mathrm{K}_{\mathrm{e}}\right)$ & $\mathrm{k}_{\mathrm{e}}=\frac{\mathrm{Sh} \cdot \mathrm{D}_{\mathrm{m}}}{\mathrm{d}_{\mathrm{p}}}$ & Muzic et al. (2010) \\
Schmidt Number & $\mathrm{Sc}=\frac{\mu_{\mathrm{m}}}{\rho_{\mathrm{L}} \mathrm{D}_{\mathrm{m}}}$ & Muzic et al. (2010) \\
Sherwood Number & $\mathrm{Sh}=2+1,1 \mathrm{Re}^{0,6} \mathrm{Sc}^{1 / 3}$ & Ruthven (1984) \\
Reynolds Number & $\mathrm{Re}=\frac{\rho_{\mathrm{L}} \mathrm{V}_{\mathrm{s}} \mathrm{d}_{\mathrm{p}}}{\mu_{\mathrm{m}}}$ & Muzic et al. (2010) \\
\hline
\end{tabular}


Table 4. Additional mathematical expressions of the model.

\begin{tabular}{|c|c|c|}
\hline Name & Model & Reference \\
\hline Surface velocity $\left(\mathrm{v}_{\mathrm{s}}\right)$ & $\mathrm{v}_{\mathrm{S}}=\frac{\mathrm{Q}}{\mathrm{S}}$ & Ruthven (1984) \\
\hline Interstitial velocity ( $\mathrm{u}_{0}$ ) & $\mathrm{u}_{0}=\frac{\mathrm{v}_{\mathrm{s}}}{\mathrm{g}}$ & Ruthven (1984) \\
\hline Axial dispersion $\left(\mathrm{D}_{\mathrm{L}}\right)$ & $\frac{\mathrm{D}_{\mathrm{L}}}{\mathrm{u}_{0} \mathrm{~d}_{\mathrm{p}}}=\frac{20}{\varepsilon}\left(\frac{\stackrel{\mathrm{D}}{\mathrm{D}}}{\mathrm{u}_{0} \mathrm{~d}_{\mathrm{p}}}\right)+\frac{1}{2}$ & Ruthven (1984) \\
\hline Molecular diffusivity $\left(\mathrm{D}_{\mathrm{m}}\right)^{1}$ & $\mathrm{D}_{\mathrm{SO}_{4}}{ }^{-}=\frac{\left(\mathrm{Z}_{+}+\left|\mathrm{Z}_{-}\right|\right) \mathrm{D}^{0} \mathrm{Na}_{+} \mathrm{D}^{0} \mathrm{SO}_{4}{ }^{-}}{\mathrm{Z}_{+} \mathrm{D}^{0}{ }_{\mathrm{Na}^{+}}+\left|\mathrm{Z}_{-}\right| \mathrm{D}^{0}{ }_{\mathrm{SO}_{4}}^{-}}$ & Muzic et al. (2010). \\
\hline
\end{tabular}

${ }^{1} \mathrm{Z}+\mathrm{e} \mathrm{Z}$ - are the positive and negative values of the loads of the ions involved. $\mathrm{D}^{\circ}{ }_{\mathrm{Na}}$ and $\mathrm{D}^{\circ} \mathrm{so}_{4}^{-}$are the diffusivity of $\mathrm{Na}^{+}$e $\mathrm{SO}_{4}^{-}$ions in aqueous solution, respectively, $1.3334 \cdot 10^{-5}$ and $1.06 \cdot 10^{-5} \mathrm{~cm}^{2} / \mathrm{s}$ (Ramos et al., 2010).

attempting to capture better the dynamic behavior of the sulfate concentration (mainly due to the breakpoint that moves along the column). It is important to highlight that values of error tolerance, as small as 1 $\times 10^{-5}$, were set in the solver in MATLAB to provide accurate solution over time.

\section{Particle filter implementation}

As the measurements present uncertainties (noise), it was assumed that the standard deviation of the data of sulfate concentration at the outlet of the column was equal to $5 \%$ of the observed concentration. In most practical applications, information regarding measurement uncertainties is not available. However, the uncertainty level considered in this paper is superior to the specifications of the ICP-OES equipment (Spectro Cirus CCD) used to obtain the experimental measurements of Guimarães and Leão (2014a). This was selected intentionally, to evaluate the performance of the proposed tool when sufficient information is not available.

The estimated values for the states were obtained in the sampling step performed as a random walk given by $x_{k}=x_{k-1}+v_{k}$. In this equation, the vectors $x_{k-1}$ are the initial guesses or the prior estimates and $v_{k}$ is the uncertainty of the evolution model taken as a normal distribution, such that $\mathrm{v}_{\mathrm{k}} \sim \mathrm{N}\left(0, \sigma_{\mathrm{m}}^{2}\right)$.

After developing the computational code, the following conditions were analyzed:

a) Analysis of the number of particles $\left(\mathrm{N}_{\mathrm{p}}\right)$ : according to Shenoy et al. (2013) and Chen, Morris and Martin (2005), the proper choice of the number of particles can improve the performance of the filter as much as the non-degeneration of the particles. But, high $\mathrm{N}_{\mathrm{p}}$ can result in high computational cost. Thus, to select the necessary number of particles, it was investigated by means of (i) the uncertainty of the model, (ii) the average CPU time and (iii) the error metrics. Firstly, since the evolution model may not represent adequately the physical process, the uncertainty (or degree of confidence) of the evolution model $\left(\sigma_{m}\right)$ allows verifying whether it is necessary to broaden the search space around the model response in which the particles are generated. To approximate better the a posteriori distribution, the uncertainty $\sigma_{\mathrm{m}}$ was evaluated as $5 \%, 10 \%$ and $30 \%$ of the maximum expected value of the concentration. When the value of model uncertainty is high, the filter algorithm is able to generate particles not just in the vicinity of the model response. Secondly, the average CPU time is the elapsed time spent by the filter algorithm to calculate the estimates between the sampling times. It was also used to characterize the PF. Finally, the error metrics Root Mean Square (RMS) and Mean Absolute Deviation (MAD), according to Equations 6 and 7 respectively, allow evaluating the quality of the fit between the measured and estimated values.

$$
\begin{aligned}
& \mathrm{RMS}=\sqrt{\frac{1}{\mathrm{~N}} \Sigma_{\mathrm{i}=1}^{\mathrm{N}}\left(\mathrm{C}_{\text {measured }}^{\mathrm{i}}-\mathrm{C}_{\text {estimated }}^{\mathrm{i}}\right)} \\
& \mathrm{MAD}=\frac{1}{\mathrm{~N}} \Sigma_{\mathrm{i}=1}^{\mathrm{N}}\left|\mathrm{C}_{\text {measured }}^{\mathrm{i}}-\mathrm{C}_{\text {estimated }}^{\mathrm{i}}\right|
\end{aligned}
$$

b) Feed flow rate estimation: the feed flow is the only time-varying parameter to be estimated. It was considered as a random variable, normally distributed, as $\mathrm{Q}_{\mathrm{k}}=\mathrm{Q}_{\mathrm{k}-1}+\mathrm{v}_{\mathrm{k}}, \mathrm{V}_{\mathrm{k}} \sim \mathrm{N}\left(0, \sigma_{\mathrm{q}}^{2}\right)$. This is necessary to account for the fluctuations in the pumping system during the operation. The uncertainty $\sigma_{\mathrm{q}}$ was assumed as $5 \%$ of the initial value of the feed flow as the uncertainty.

c) Autocorrelation analysis: here the concept of scaled sample autocorrelation (Box et al., 1994) was used to verify whether the PF succeeded in removing the uncertainties from the measurements. The autocorrelation analysis allows checking the correlation (or the similarity) of the residue sequence resulting from the estimation. If the PF works as expected, the residue sequence has to be an uncorrelated signal of random variables with zero mean and finite variance. In this case, the autocorrelation should look like a pattern of white noise, which can be represented by a Dirac delta function. On the other hand, if different patterns can be identified within the residue sequence, one can say that the filter was mis-specified.

d) Performance comparison with the Unscented Kalman Filter (UKF): in order to discuss better the results obtained here with the PF, the UKF approach 
was implemented to perform a comparison. Such a choice was motivated by the suitability for nonlinear systems without resorting to linearization procedures. The uncertainty of the model, the CPU time and the error metrics were also analyzed.

To avoid negative concentration in the confidence intervals, the acceptance/rejection method (also known as clipping) (Zhao et al., 2014) was used to handle the generation of particles with negative concentration. Particles within the expected limits were used for the estimation, whereas particles with negative values were discarded and others generated. This approach is important in the beginning of the concentration profile due to the values being close to zero.

In addition, the a posteriori distribution was reconstructed from the resampled particles, considering the best filter setting found in the analysis of the number of particles. For all the conditions tested, a 95\% confidence interval was considered for the estimates. Finally, the tests were performed on a computer with an Intel Core ${ }^{\mathrm{TM}} \mathrm{i} 5-3570$ processor, 4 GB RAM and 64-bit Windows OS.

\section{RESULTS AND DISCUSSION}

\section{Calibration of the Langmuir model}

The equilibrium concentration is a necessary parameter to complete the mass transfer LDF model and it was obtained according to the Langmuir model. The fitting to the experimental data (Figure 2) led to the parameters $\mathrm{b}$ and $\mathrm{q}_{\max }$ being equal to 0.04 and 60.32 , respectively, with $\mathrm{R}^{2}$ of $95.5 \%$. Considering the value of adsorbate per unit of adsorbent of $57.2519 \mathrm{mg} / \mathrm{L}$ (Guimarães and Leão, 2014a), the equilibrium concentration was $427.8 \mathrm{mg} / \mathrm{L}$.

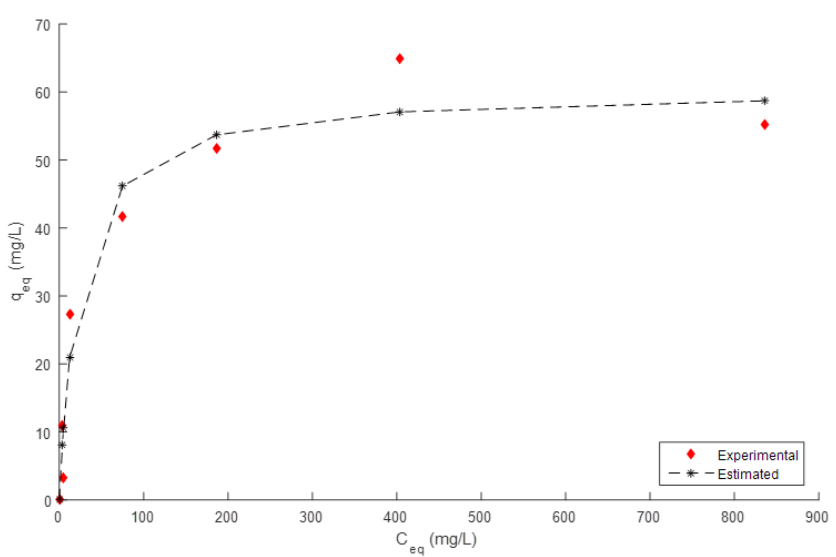

Figure 2. Fitting of the Langmuir model to the batch data from Guimarães and Leão (2014a).

\section{Grid convergence analysis $(\mathbf{N})$}

Due to the application of the method of lines, the number $\mathrm{N}$ of discretization points was evaluated. The results of the relative simulation errors are presented in Table 5 .
Table 5. Grid convergence analysis based on the relative simulation errors, regarding 1000 points as the reference.

\begin{tabular}{ccccc}
\hline & $\begin{array}{c}\text { Position } \\
\text { in the column } \\
(\mathbf{x})\end{array}$ & \multicolumn{3}{c}{ Dimensionless time $(\tau)$} \\
\cline { 3 - 5 } & & $\mathbf{0 . 7 1 7 4}$ & $\mathbf{1 . 5 2 4 5}$ & $\mathbf{2 . 3 3 1 6}$ \\
\hline 10 & 0.269029 & 0.676022 & 0.07014 \\
50 & 0.5 & 1.245502 & 0.133156 & 0.01002 \\
100 & & 0.595073 & 0.061457 & 0 \\
1,000 & & 0 & 0 & 0 \\
10 & & 8.431953 & 1.929116 & 0.161714 \\
50 & \multirow{2}{*}{1.0} & 0.332840 & 0.044863 & 0 \\
100 & & 0.073964 & 0.010107 & 0 \\
1,000 & & 0 & 0 & 0 \\
\hline
\end{tabular}

As expected, the relative errors decreased according to the increase in the number of discretization points. This means that increasing refinement leads the simulated concentration steadily to the reference condition. Moreover, with the time increase, the relative errors also decreased. In this case, the process tends to reach the saturation condition due to the movement of the breakthrough curve toward the column outlet. Thus, the concentration rises up to the feed concentration. For this reason, regardless of the number of discretization points, the relative errors tend to zero. Consequently, the discretization was performed with 50 points in the axial direction of the column, since the errors were less than $1.5 \%$ when compared to the most refined grid.

\section{Analysis of the number of particles $(N)$}

Because one of the drawbacks of PFs is the computational time, it is important to find the ideal number of particles, especially when the CPU time of the filter must be shorter than the process sampling time. The analysis performed considered the uncertainty of the model, the average CPU time and the error metrics, resulting in the data shown in Table 6.

It can be observed that the error metrics decrease as the number of particles increases, demonstrating an improvement in the filter performance. Although the

Table 6. Analysis of the number of particles $\left(\mathrm{N}_{\mathrm{p}}\right)$, according to the uncertainty of the model, the average CPU time and the error metrics (RMS and MAD).

\begin{tabular}{ccccc}
\hline $\mathbf{N}_{\mathbf{p}}$ & $\boldsymbol{\sigma}_{\mathbf{m}}$ & $\begin{array}{c}\mathbf{C P U} \\
\text { time (s) }\end{array}$ & $\mathbf{R M S}$ & MAD \\
\hline \multirow{3}{*}{10} & $5 \%$ & & 0.3703 & 0.2350 \\
& $10 \%$ & 0.4837 & 0.3107 & 0.1958 \\
& $30 \%$ & & 0.1267 & 0.0729 \\
100 & $5 \%$ & & 0.3386 & 0.2108 \\
& $10 \%$ & 2.3458 & 0.2646 & 0.1550 \\
& $30 \%$ & & 0.0118 & 0.0078 \\
500 & $5 \%$ & & 0.3164 & 0.1985 \\
& $10 \%$ & 11.0629 & 0.1737 & 0.0940 \\
1000 & $\mathbf{5 0 \%}$ & & 0.0034 & 0.0028 \\
& $\mathbf{5} \%$ & & 0.3065 & 0.1912 \\
& $30 \%$ & 18.7912 & 0.1857 & 0.1041 \\
\end{tabular}


way that each error metric is calculated is different, they are based on the difference between the measured and estimated values. This result also indicates that the estimation accuracy of the PF is improved as well. The CPU time of the filter increased according to the number of particles. However, in all cases, the time spent was much less than the process sampling time (which was $10 \mathrm{~min}$ in the studies by Guimarães and Leão, 2014a). This means that a filter with a high number of tested particles would not be a limiting factor for use as an online estimation tool.

Considering the effect of the uncertainty of the model, the error metrics decreased as the uncertainty increased from $5 \%$ to $30 \%$. This relates to the fact that the filter needs a broader search space around the model response to draw the particles, in order to estimate more effectively the sulfate concentration.

To understand this, it is necessary to note that the filter with a model uncertainty of $5 \%$ or $10 \%$, even with the increase in the number of particles, did not experience much reduction of RMS and MAD. This means that the lower uncertainty value of the evolution model cannot represent the whole dynamics of the process. Thus, in this case, good information is required to ensure better performance of the algorithm. However, when such information is weak, the use of greater uncertainty values can broaden the search space for the generation of the particles, which increases the feasibility of a better approximation of the $a$ posteriori distribution.

Indeed, with model uncertainty of $30 \%$, the values of the error metrics decreased considerably. However, between the cases with 500 and 1000 , such particle metrics changed very little, at the expense of increasing the CPU time by approximately $70 \%$.

Thus, in the face of this analysis, the filter with 500 particles and $30 \%$ model uncertainty was selected to perform the estimation. Such a configuration showed a CPU time of about $11 \mathrm{~s}$ and the lowest values of the RMS and MAD, which meets the needs of a monitoring scheme arranged online.

\section{Estimation of the dynamic behavior with the PF}

To give support to the best configuration of the PF found in the previous section, Figure 3 presents the dynamic behavior, also called the breakthrough curve, of the $\mathrm{SO}_{4}{ }^{2-a d s o r p t i o n}$ in the fixed-bed column. This curve considers only the experimental data of sulfate adsorption at the column outlet obtained by Guimarães and Leão (2014a). It can be seen that the estimated values of the sulfate concentration were obtained with great accuracy, within a confidence interval of $95 \%$. This shows that the filter used was able to filter the uncertainties from the measuring equipment.

Figure 4 shows the dynamic behavior of the estimation for the feed flow rate. This input parameter

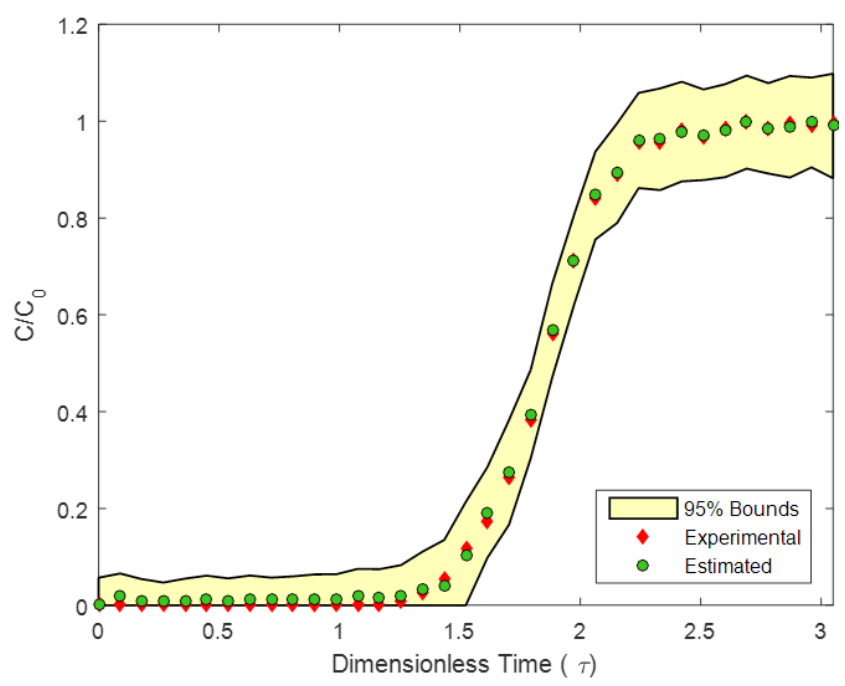

Figure 3. Filtering of the sulfate concentration measured at the column outlet with the SIR filter, using 500 particles and model uncertainty of $30 \%$.

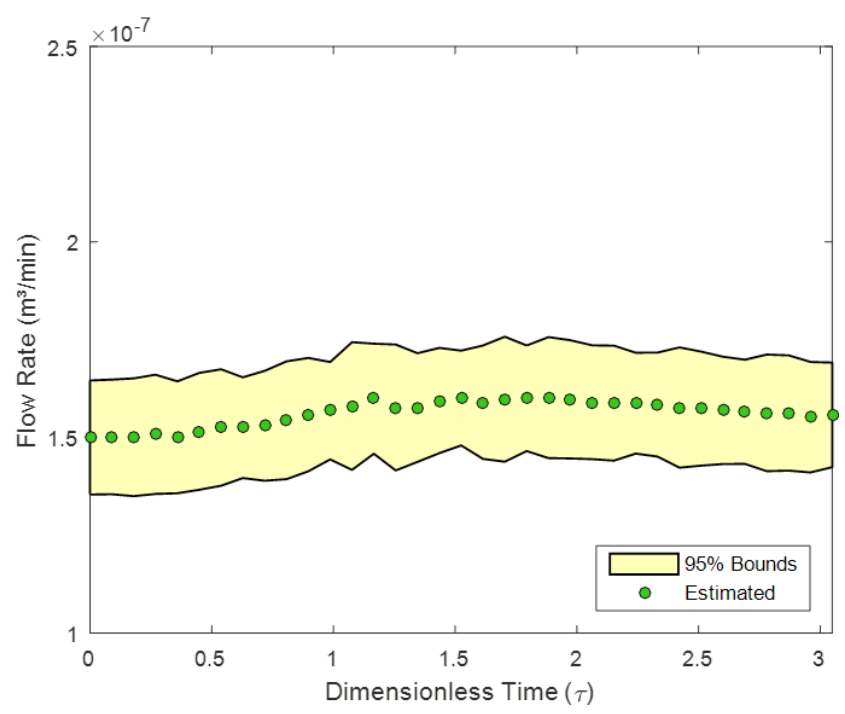

Figure 4. Estimation of the feed flow rate of the column with the SIR filter, using 500 particles and model uncertainty of $30 \%$.

was also satisfactorily estimated under the framework studied here. The mean value of the estimate of this variable exhibits a slight increase with time. However, with a $95 \%$ confidence level, the feed flow could be taken as a constant input.

The PF also allows estimation of the latent states, which are not measured. In this case, the breakthrough curve can be presented, but indicating the behavior of the sulfate removal at different bed positions over time (Figure 5). As the axial domain was discretized into 100 points, the behavior of the adsorption along the column could be visualized through curves generated at the beginning of the bed region in which adsorption was initiated $(\mathrm{z}=0)$; at intermediate positions, $(\mathrm{z}=$ $\left.[0.2245,0.4988,0.7347]^{\mathrm{T}}\right)$; and finally at the outlet $(\mathrm{z}$ $=1)$. 


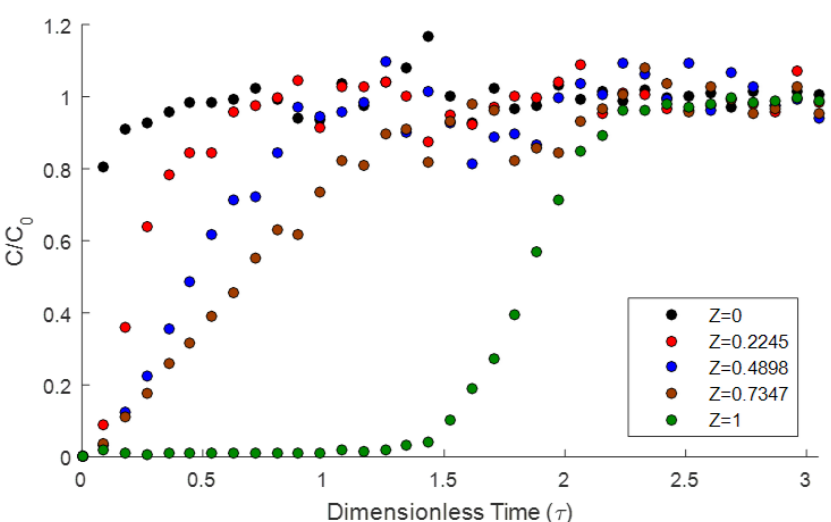

Figure 5. Behavior of sulfate removal at different positions of the adsorbent bed over time.

In Figure 5, at the beginning of the contact between the feed stream and the adsorbent bed, the sulfate loading in the resin is practically total since the bed presents free adsorption sites. This process happens until the moment that this adsorption zone begins to saturate, which is indicated by the stability of the lines over time.

This behavior was also confirmed by Calero et al. (2009), who reported that, as these adsorption zones run through the column, the adsorbent bed tends to be loaded. When the adsorption front reaches the last bed position, the final sulfate concentration in the effluent solution from the column tends to increase until the initial or affluent concentration is equal to that in the column. The reason is the lack of adsorption sites, indicating the need for regeneration or exchange of the resins.

\section{Autocorrelation analysis of the residue}

In addition to the results shown here, another way to show the performance of the filter in filtering the uncertainties is to use an autocorrelation function of the difference between the estimated and the measured values. This difference represents the residue sequence resulting from the estimation. Since the measured values can be considered as the exact value with added measurement noise, and the estimated value is expected to be the value without noise, the difference between them is expected to represent the measurement noise. As shown Figure 6, it is possible to illustrate the correlation of noise.

It is noted in Figure 6 that the residue signal only presents significant autocorrelation (red stems) at the time lag of zero, where it equals unity. Elsewhere, for any other time-lagged copies of the signal, the result suggests that the autocorrelation is significantly null, since the values lie inside the $95 \%$ confidence bounds (blue lines). As expected, this result is similar to a Dirac delta function, which is the pattern of white noise correlogram. This indicates that the filter was able to estimate values by removing the uncertainties

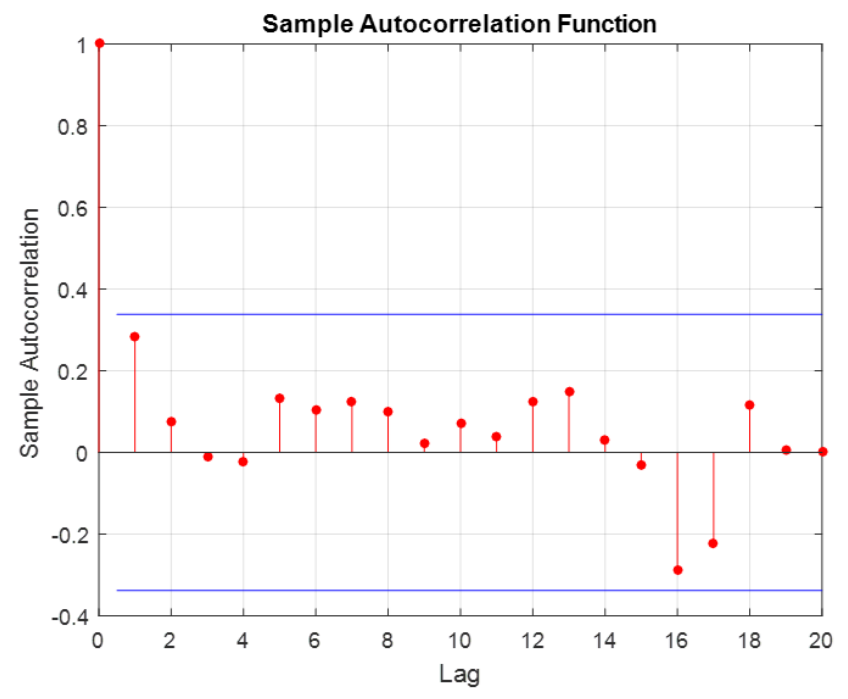

Figure 6. Autocorrelation for the residue sequence resulting from the estimation.

associated with the measurements, since the estimation residue shows no correlation with its timelagged series. If the estimator had failed in filtering such uncertainties, correlations could be seen all over the time lags. Clearly, the proposed autocorrelation analysis in this context confirmed that the filter used in this study was able to remove all the uncertainties.

\section{Performance comparison to the UKF}

The comparison is given in Table 7, considering the best number of particles; that is, 500 particles for the $\mathrm{PF}$. The average CPU time of the PF is about 7.5 times greater than that of the UKF. The results also show that, with a model uncertainty of $5 \%$ and $10 \%$, the UKF performs better, since the error metrics are less than those of the PF. This is because the PF needs a broader search space to estimate more effectively the sulfate concentration, as already discussed. Thereafter, when the model uncertainty is increased to $30 \%$, the error metrics for the PF become much smaller compared to the UKF. If it is recalled that the measurements were obtained with a sampling time of $10 \mathrm{~min}$, the result of the PF with model uncertainty of $30 \%$ is very satisfactory at filtering the measurements.

Moreover, Figure 7 shows the performance over time for the UKF and the PF. A model uncertainty of $30 \%$ and measuring uncertainty of $5 \%$ of the measured value

Table 7. Performance results for the PF with 500 particles and the UKF.

\begin{tabular}{ccccc}
\hline \multirow{2}{*}{ Filter } & \multirow{2}{*}{$\boldsymbol{\sigma}_{\mathrm{m}}$} & $\begin{array}{c}\text { CPU } \\
\text { time (s) }\end{array}$ & \multicolumn{2}{c}{ Error metrics } \\
\cline { 4 - 5 } & $5 \%$ & & 0.3164 & MAD \\
\hline \multirow{3}{*}{$\mathrm{PF}$} & $10 \%$ & \multirow{2}{*}{11.06} & 0.1737 & 0.1985 \\
& $30 \%$ & & 0.0034 & 0.0028 \\
& $5 \%$ & & 0.2098 & 0.1410 \\
$\mathrm{UKF}$ & $10 \%$ & \multirow{2}{*}{1.49} & 0.0850 & 0.0558 \\
& $30 \%$ & & 0.0229 & 0.0164 \\
\hline
\end{tabular}



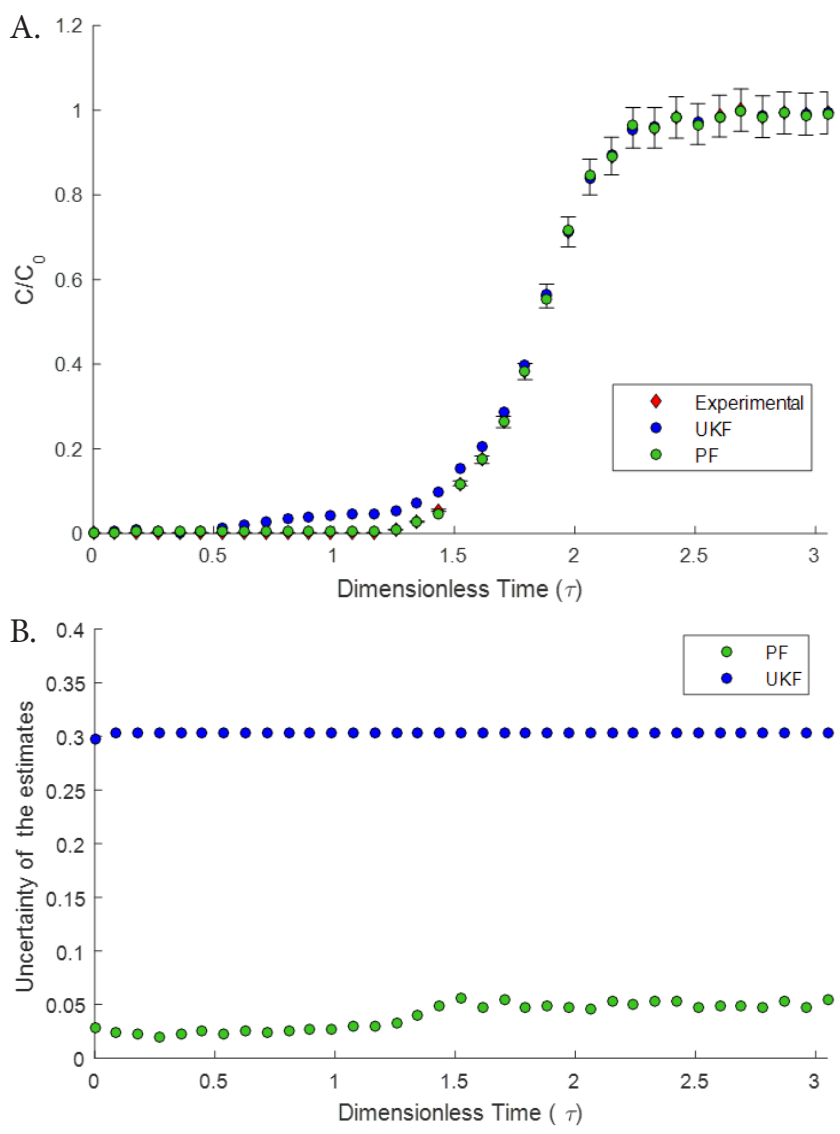

Figure 7. Comparison of the Particle Filter (PF) with the usual Unscented Kalman Filter (UKF): A) the adsorption breakthrough curve; B) uncertainties of the estimates for each filter.

were considered, in order to observe how the estimation tools represent the adsorption breakthrough curve.

As indicated in Table 7, the PF approximated very accurately the measurements of sulfate concentrations within the degree of uncertainty of the data (Figure 7A). The UKF can also represent the process; however, it failed at the breakpoint (i.e., the moment at which saturation of the fixed bed begins). But, as shown in Figure 7B, this result is reached at the expense of the highest-value uncertainties of the estimates, which is not satisfactory. Thus, it is clear that the PF performed very accurately, and would lead to a narrower confidence interval for any confidence level when compared to the UKF.

\section{A posteriori distribution reconstruction}

The previous results were shown in terms of the arithmetic mean of the particles. However, the representativeness of the mean as the estimative depends on the shape of the a posteriori distribution approximated by the resampled particles at each time. In this regard, Figure 8 presents the reconstruction of the a posteriori distribution for the concentration at the column outlet at different time instants.

It can be observed that the particle probability is

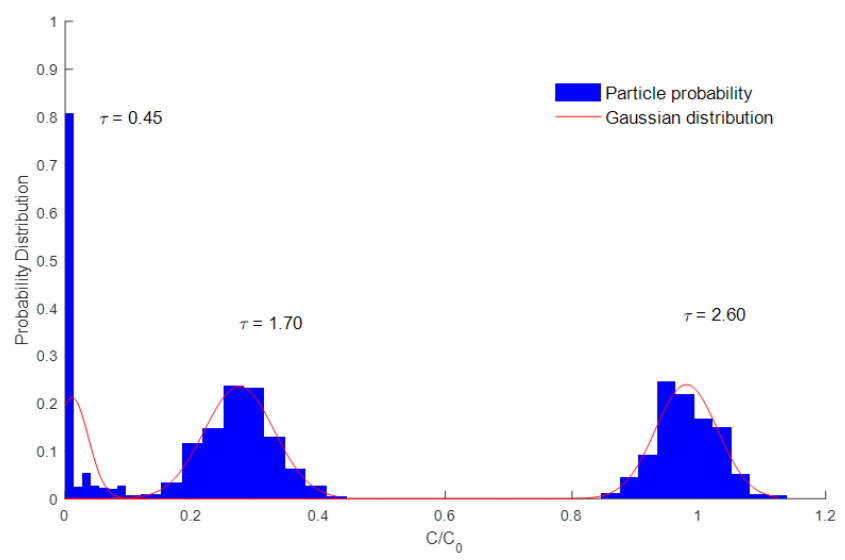

Figure 8. Reconstruction of the posteriori distribution.

similar to a Gaussian distribution. Compared to Figure 3 , the mean of each reconstructed distribution equals the filtered sulfate concentration at the respective time. This confirms the performance in filtering the uncertainties and suggests that the mean of the resampled particles represents the estimate of the state variable.

Moreover, one could also suggest that a tool from the family of KFs would suffice to estimate the variables in this case. This is due to the fact that these filters are indicated exclusively for Gaussian systems. However, recalling the uncertainties of the estimates shown in Figure 7B, one can see that, even though the reconstructed distributions look like a Gaussian distribution, the UKF did not provide accurate estimates. On the contrary, the PF succeeded at approximating more accurately the a posteriori distribution of the state variables. This result was expected, since the PF is a more general tool.

\section{CONCLUSIONS}

Computational tools are paramount in the search for improvements in industrial processes. These tools are able to provide important information about dynamic behavior, as well as assisting in more accurate monitoring.

In this study, the SIR PF was proposed for the estimation of states and parameters of a fixed-bed adsorption column capable of removing sulfate from industrial water. The results obtained were quite satisfactory, showing that the PF was able to remove the uncertainties in order to approximate the actual process behavior from the experimental measurements.

Finally, it is important to emphasize the great applicability of the PF in the field of effluent treatment processes, more specifically in adsorption columns, as it is capable of providing fast results for real-time monitoring. Moreover, since no published articles applying such methodology in the monitoring of adsorption columns were found, this work presents a great academic contribution. 


\section{ACKNOWLEDGEMENTS}

Financial support from the funding agencies FAPES, FINEP, FAPEMIG, CNPq, CAPES (Finance Code 001) and Vale is gratefully appreciated.

\section{NOMENCLATURE}

$a_{v} \quad$ Surface area of the adsorbent particle $\left(\mathrm{m}^{2}\right)$

$\mathrm{b}^{\mathrm{v}} \quad$ Langmuir's constant $\left(\mathrm{m}^{3} / \mathrm{mg}\right)$

C Concentration of adsorbate in the liquid phase $\left(\mathrm{mg} / \mathrm{m}^{3}\right)$

$\mathrm{C}_{0} \quad$ Initial concentration $\left(\mathrm{mg} / \mathrm{m}^{3}\right)$

$\mathrm{C}_{\mathrm{eq}} \quad$ Equilibrium concentration of the adsorbate in solution $\left(\mathrm{mg} / \mathrm{m}^{3}\right)$

$\mathrm{C}_{\mathrm{j}} \quad$ Concentration of the specie $\mathrm{j}$ in the liquid phase $\left(\mathrm{mg} / \mathrm{m}^{3}\right)$

$\mathrm{D}_{\mathrm{L}} \quad$ Axial dispersion's coefficient $\left(\mathrm{m}^{2} / \mathrm{min}\right)$

$\mathrm{D}_{\mathrm{m}} \quad$ Solute's molecular diffusivity in the fluid phase $\left(\mathrm{m}^{2} / \mathrm{min}\right)$

$\mathrm{D}^{\circ}{ }_{\mathrm{Na}} \quad$ Sodium molecular diffusivity $\left(\mathrm{m}^{2} / \mathrm{min}\right)$

$\mathrm{D}^{\circ}{ }_{\mathrm{SO}_{4}} \quad$ Sulfate molecular diffusivity $\left(\mathrm{m}^{2} / \mathrm{min}\right)$

$\mathrm{d}_{\mathrm{p}} \quad$ Particle diameter $(\mathrm{m})$

$\mathrm{k}_{\mathrm{e}}^{\mathrm{p}} \quad$ Coefficient of mass transfer in the liquid film external to the particle $(\mathrm{m} / \mathrm{min})$

L Bed height (m)

$\mathrm{Pe} \quad$ Peclet number (dimensionless)

Q Flow rate $\left(\mathrm{m}^{3} / \mathrm{min}\right)$

$\mathrm{q}_{\mathrm{eq}} \quad$ Amount of adsorbate adsorbed by the adsorbent $(\mathrm{mg} / \mathrm{g})$

$\mathrm{q}_{\max } \quad$ Maximum amount of adsorbed adsorbed (mg/g)

Re Reynolds number (dimensionless)

$r_{p} \quad$ Particle radius $(m)$

S Cross-sectional area of the column $\left(\mathrm{m}^{2}\right)$

Sc Schmidt number (dimensionless)

Sh Sherwood number (dimensionless)

$\mathrm{t} \quad$ Column operating time $(\mathrm{min})$

$\mathrm{u}_{0} \quad$ Interstitial velocity $(\mathrm{m} / \mathrm{min})$

$\mathrm{v}_{\mathrm{s}} \quad$ Surface velocity $(\mathrm{m} / \mathrm{min})$

$\mathrm{x} \quad$ Spatial coordinate (dimensionless)

z $\quad$ Axial coordinate along the column (m)

$\rho_{\mathrm{L}} \quad$ Density of the adsorbent or bed $\left(\mathrm{mg} / \mathrm{m}^{3}\right)$

$\mu_{\mathrm{m}} \quad$ Viscosity of the mixture ( $\mathrm{mg} / \mathrm{m}$.min)

$\varepsilon \quad$ Bed porosity (dimensionless)

q Mean concentration of adsorbate in the adsorbent $\left(\mathrm{mg} / \mathrm{m}^{3}\right)$

$\tau$

Coordinate of time (dimensionless)

\section{REFERENCES}

Abdulgader, H. A., Kochkodan, V., Hilal, N. Hybrid ion exchange-Pressure driven membrane processes in water treatment: A review. Separation and Purification Technology, 116, 253-264 (2013). https://doi.org/10.1016/j.seppur.2013.05.052
Aksu, Z., Gönen, F. Biosorption of phenol by immobilized activated sludge in a continuous packed bed: prediction of breakthrough curves. Process Biochemistry, 39, 599-613 (2004). https:// doi.org/10.1016/S0032-9592(03)00132-8

Altig, D., Christiano, L. J., Eichenbaum, M., Lind J. Firm-specific capital, nominal rigidities and the business cycle. Review of Economic Dynamics, 14, 225-247 (2011). https://doi.org/10.1016/S00329592(03)00132-8

Arulampalam, M. S., Maskell, S., Gordon, N., Clapp, T. A tutorial on particle filters for online nonlinear/non-Gaussian Bayesian tracking. IEEE Transactions on Signal Processing, 50, 174-188 (2002). https://doi.org/10.1109/78.978374

Barros, M. A. S. D., Silva, E. A., Arroyo, P. A., Tavares, C. R. G., Schneider, R. M., Suszek, M., Aguiar, E. F. S. Removal of Cr (III) in the fixed bed column and batch reactors using as adsorbent zeolite $\mathrm{NaX}$. Chemical Engineering Science, 59, 5959-5966 (2004). https://doi.org/10.1016/j.ces.2004.07.040

Berardi, M., Vurro, M., The numerical solution of Richards' equation by means of method of lines and ensemble Kalman filter. Mathematics and Computers in Simulation, 125, 38-47 (2015). https://doi.org/10.1016/j.matcom.2015.08.019

Bhatnagar, A., Sillanpää, M. A review of emerging adsorbents for nitrate removal from water. Chemical Engineering Journal, 168, $493-504$ (2011). https:// doi.org/10.1016/j.cej.2011.01.103

Box, G., Jenkins, G. M., Reinsel, G. C. Time Series Analysis: Forecasting \& Control (3rd Edition) (1994). https://doi.org/10.1111/j.14679892.2009.00643.x

Burkert, C. A. V., Barbosa, G. N. O., Mazutti, M. A., Maugeri, F. Mathematical modeling and experimental breakthrough curves of cephalosporin $\mathrm{C}$ adsorption in a fixed-bed column. Process Biochemistry, 46, 1270-1277 (2011). https://doi. org/10.1016/j.procbio.2011.02.016

Calero, M., Hernáinz, F., Blázquez, G., Tenorio, G., Lara, M. A. M. Study of Cr (III) biosorption in a fixed-bed column. Journal of Hazardous Materials, 171, 886-893 (2009). https://doi.org/10.1016/j. jhazmat.2009.06.082

Chatzi, E. N., Smyth, A. W. The unscented Kalman filter and particle filter methods for nonlinear structural system identification with non-collocated heterogeneous sensing. Structural Control and Health Monitoring, 16, 99-123 (2009). https://doi. org/10.1002/stc. 290

Chen, T., Morris, J., Martin, E. Dynamic data rectification using particle filters. Computers \& Chemical Engineering, 32, 451-462 (2008). https:// doi.org/10.1016/j.compchemeng.2007.03.012 
Chen, T., Morris, J., Martin, E. Particle filters for state and parameter estimation in batch processes. Journal of Process Control, 15, 665-673 (2005). https://doi.org/10.1016/j.jprocont.2005.01.001

$\mathrm{Chu}, \mathrm{K} . \mathrm{H}$. Fixed bed sorption: setting the record straight on the Bohart-Adams and Thomas models. Journal of Hazardous Materials, 177, 1006-1012 (2010). https://doi.org/10.1016/j.jhazmat.2010.01.019

Dias, A. C. S. R., Silva, W. B. da, Dutra, J. C. S. Propylene Polymerization Reactor Control and Estimation Using a Particle Filter and Neural Network. Macromolecular Reaction Engineering, 11, 1-20 (2017). https://doi.org/10.1002/ mren.201700010

Dong, Y., Lin, H. Competitive adsorption of $\mathrm{Pb}$ (II) and $\mathrm{Zn}$ (II) from aqueous solution by modified beer lees in a fixed bed column. Process Safety and Environmental Protection, 111, 263-269, (2017). https://doi.org/10.1016/j.psep.2017.06.016

Dou, W., Zhou, Z., Jiang, L. M., Jiang, A. Huang, R., Tian, X., Zhang, W., Chen, D. Sulfate removal from wastewater using ettringite precipitation: Magnesium ion inhibition and process optimization. Journal of Environmental Management, 196, 518-526 (2017). https://doi.org/10.1016/j. jenvman.2017.03.054

Doucet, A., Godsill, S., Andrieu C. On sequential Monte Carlo sampling methods for Bayesian filtering. Statistics and Computing, 10, 197-208 (2000). https://doi.org/10.1023/A:1008935410038

Emigdio, Z. F., Abatal, M., Bassam, A., Trujillo, L., Smith, P. J., Hamzaoui, Y. E., Modeling the adsorption of phenols and nitrophenols by activated carbon using genetic programming. Journal of Cleaner Production, 161, 860-870 (2017). https:// doi.org/10.1016/j.jclepro.2017.05.192

Fakhroleslam, M., Fatemi, S., Boozarjomehry, R. B. A switching decentralized and distributed extended Kalman filter for pressure swing adsorption processes. International Journal of Hydrogen Energy, 41, 23042-23056 (2016). https://doi. org/10.1016/j.ijhydene.2016.08.120

Guimarães, D., Leao, V. A., Batch and fixed-bed assessment of sulphate removal by the weak base ion exchange resin Amberlyst A21. Journal of Hazardous Materials, 280, 209-215 (2014a). https://doi.org/10.1016/j.jhazmat.2014.07.071

Guimarães, D., Leao, V. A. Fundamental aspects related to batch and fixed-bed sulfate sorption by the macroporous type 1 strong base ion exchange resin Purolite A500. Journal of Environmental Management, 145, 106-112 (2014b). https://doi. org/10.1016/j.jenvman.2014.06.006

Guzman, D. N. E., Córdova, C. F. J., Regalado, S. E., Cancino, L. M., Medrano, L. J. A., Reyes, G. R. B. A mass transfer model for the fixed- bed adsorption of ferulic acid onto a polymeric resin: axial dispersion and intraparticle diffusion. Environmental Technology, 37, 1914-1922 (2016). https://doi.org/10.1080/09593330.2015.1135993

Haghsheno, R., Mohebbi, A., Hashemipour, H., Sarrafi, A., Study of kinetic and fixed bed operation of removal of sulfate anions from an industrial wastewater by an anion exchange resin. Journal of Hazardous Materials, 166, 961-966 (2009). https:// doi.org/10.1016/j.jhazmat.2008.12.009

Harjunkoski, I. Future of control and operations in the era of industrial internet of things. Computer Aided Chemical Engineering, 40, 2275-2280 (2017). https://doi.org/10.1016/B978-0-444-639653.50381-0

Kalyanaraman, J., Kawajiri, Y., Realff, M. J., Bayesian Estimation, Uncertainty Propagation and Design of Experiments for $\mathrm{CO}_{2}$ Adsorption on Amine Sorbents. Proceedings of the $8^{\text {th }}$ International Conference on Foundations of Computer-Aided Process Design, 34, 345-350 (2014). https://doi. org/10.1016/B978-0-444-63433-7.50042-0

Kankeu, F. E., Mittal, F., Waanders, F., Ray, S. S. Thermodynamic properties and adsorption behaviour of hydrogel nanocomposites for cadmium removal from mine effluents. Journal of Industrial and Engineering Chemistry, 48, 151-161 (2017). https://doi.org/10.1016/j.jiec.2016.12.033

Khatibisepehr, S., Huang, B., Khare, S. Design of inferential sensors in the process industry: A review of Bayesian methods. Journal of Process Control, 23, 1575-1596 (2013). https://doi.org/10.1016/j. jprocont.2013.05.007

Lamien, B., Orlande, H. R. B., Eliçabe, G. E. Particle Filter and Approximation Error Model for State Estimation in Hyperthermia. Journal of Heat Transfer, 139, 1-12 (2016). https://doi. org/10.1115/1.4034064

Lopez, F., Zhang, L., Beaman, J., Mok, A. Implementation of a particle filter on a GPU for nonlinear estimation in a manufacturing remelting process. Advanced Intelligent Mechatronics, 340-345 (2014). https://doi.org/10.1109/ AIM.2014.6878102

Lopez, F., Zhang, L., Mok, A., Beaman, J. Particle filtering on GPU architectures for manufacturing applications. Computers in Industry, 71, 116-127 (2015). https://doi.org/10.1016/j. compind.2015.03.013

Marques, R. A. G., Silva, W. B., Hoffmann, R., Dutra, J. C. S., Coral, F. Sequential state inference of engineering systems through the particle move-reweighting algorithm. Computational \& Applied Mathematics, 1, 1-17 (2017). https://doi. org/10.1007/s40314-017-0506-1 
Muzic, M., Gomzi, Z., Bionda, K. S. Modeling of the Adsorptive Desulfurization of Diesel Fuel in a Fixed-Bed Column. Chemical Engineering \& Technology, 33, 1137-1145 (2010). https://doi. org/10.1002/ceat.201000013

Orlande, H, R. B., Colaço, M. J., Dulikravich, G. S., Vianna, F. L. V., Silva, W. B. da, Fonseca, H. M., Fudym, O. Tutorial 10 Kalman and Particle filters. Advanced Spring School: Thermal Measurements and Inverse Techniques, 5, 1-39 (2011). https://doi. org/10.1201/b10918

Orlande, H, R. B., Colaço, M., Dulikravich, G., Vianna, F., Silva, W. da, Fonseca, H., Fudym, O. State estimation problems in heat transfer. International Journal for Uncertainty Quantification, 2, 1-20 (2012). https://doi.org/10.1615/ Int.J.UncertaintyQuantification.2012003582

Orlande, H. R. B., Dulikravich, G. S., Neumayer, M., Watzenig, D., Colaço, M. J. Accelerated bayesian inference for the estimation of spatially varying heat flux in a heat conduction problem. Numerical Heat Transfer, Part A: Applications, 65, 1-25 (2014). https://doi.org/10.1080/10407782.2013.81 2008

Orlande, H. R. B., Dulikravich, G., Colaço, M. Application of Bayesian filters to heat conduction problem. In EngOpt 2008 - International Conference on Engineering Optimization, 1-5, Rio de Janeiro (2008).

Otero, M., Zabkova, M., Rodrigues, A. E. Comparative study of the adsorption of phenol and salicylic acid from aqueous solution onto nonionic polymeric resins. Separation and purification Technology, 45, 86-95 (2005). https://doi.org/10.1016/j. seppur.2005.02.011

Ramos, L. R., Utrilla, J. R., Castillo, N. A. M., Polo, M. S. Kinetic modeling of fluoride adsorption from aqueous solution onto bone char. Chemical Engineering Journal, 158, 458-467 (2010). https:// doi.org/10.1016/j.cej.2010.01.019

Rengaraj, S., Yeon, J. W., Kim, Y., Jung, Y., Ha, Y. K., Kim, W. H. Adsorption characteristics of $\mathrm{Cu}$ (II) onto ion exchange resins $252 \mathrm{H}$ and $1500 \mathrm{H}$ : kinetics, isotherms and error analysis. Journal of Hazardous Materials, 143, 469-477 (2007). https:// doi.org/10.1016/j.jhazmat.2006.09.064

Ricker, N. L., Lee, J. H. Nonlinear modeling and state estimation for the Tennessee Eastman challenge process. Computers \& Chemical Engineering, 19, 983-1005 (1995). https://doi.org/10.1016/00981354(94)00113-3

Ruthven, D. M. Principles of Adsorption and Adsorption Processes. John Wiley and Sons, New York (1984).

Sajid, M., Nazal, M. K., Ihsanullah, B. N., Osman, A. M. Removal of heavy metals and organic pollutants from water using dendritic polymers based adsorbents: A critical review. Separation and Purification Technology, 191, 400-423 (2017). https://doi.org/10.1016/j.seppur.2017.09.011

Schwiegelshohn, F., Ossovski, E., Hübner, M. A resampling method for parallel particle filter architectures. Microprocessors and Microsystems, 47, 314-320 (2016). https://doi.org/10.1016/j. micpro.2016.07.017

Shafeeyan, M. S., Daud, W. M. A. W., Shamiri, A. A review of mathematical modeling of fixedbed columns for carbon dioxide adsorption. Chemical Engineering Research and Design, 92, 961-988 (2013). https://doi.org/10.1016/j. cherd.2013.08.018

Shakeri, F., Dehghan, M. The method of lines for solution of the one-dimensional wave equation subject to an integral conservation condition. Computers and Mathematics with Applications, 56, 2175-2188 (2008). https://doi.org/10.1016/j. camwa.2008.03.055

Shao, X., Huang, B., Lee, J. M. Constrained Bayesian state estimation-A comparative study and a new particle filter based approach. Journal of Process Control, 20, 143-157 (2010). https://doi. org/10.1016/j.jprocont.2009.11.002

Shenoy, A. V., Prakash, J., Mcauley, K. B., Prasad, V., Shah, S. L., Pratical issues in the application of the particle filter for estimation of chemical processes. In XVIII International Federation of Automatic Control World Congress, 2773-2778, Milano (2011). https://doi.org/10.3182/201108286-IT-1002.03272

Shenoy, A. V., Prakash, J., Prasad, V., Shah, S. L., Mcauley, K. B. Practical issues in state estimation using particle filters: Case studies with polymer reactors. Journal of Process Control, 23, 120-131 (2013). https://doi.org/10.1016/j. jprocont.2012.09.003

Silva, W. B., Dutra, J. C. S., Abreu, L. A. S., Knupp, D. C., Silva Neto, A. J. Estimation of timewise varying boundary heat flux via bayesian filters and markov chain monte carlo method. In: II Simposio de Modelación Matemática aplicada a la Ingeniería (2016) Havana. II Simposio de Modelación Matemática Aplicada a la Ingeniería (2016).

Silva, W. B., Rochoux, M., Orlande, H. H. B., Colaco, M. J., Fudym, O., El Hafi, M., Cuenot, B., Ricci, S. Application of particle filters to regionalscale wildfire spread. High Temperatures-High Pressures, 43, 415-440 (2014).

Souza, S. M. A. G. U. de, Peruzzo L. C., Souza, A. A. U. de. Numerical study of the adsorption of dyes from textile effluents. Applied Mathematical Modelling, 32, 1711-1718 (2008). https://doi. org/10.1016/j.apm.2007.06.007 
Speekenbrink, M. A tutorial on particle filters. Journal of Mathematical Psychology, 73, 140-152 (2016). https://doi.org/10.1016/j.jmp.2016.05.006

Stelzer, I. V., Kager, J., Herwig, C. Comparison of Particle Filter and Extended Kalman Filter Algorithms for Monitoring of Bioprocesses. Computer Aided Chemical Engineering, 40, 14831488 (2017). https://doi.org/10.1016/B978-0-44463965-3.50249-X

Tait, S., Clarke, W. P., Keller, J., Batstone, D. J., Removal of sulfate from high-strength wastewater by crystallisation. Water Research, 43, 762-772 (2009). https://doi.org/10.1016/j.watres.2008.11.008

Thakare, Y. N., Jana, A. K. Performance of high density ion exchange resin (INDION225H) for removal of $\mathrm{Cu}$ (II) from waste water. Journal of Environmental Chemical Engineering, 3, 1393-1398 (2015). https://doi.org/10.1016/j.jece.2015.01.002

Vianna, F., Orlande, H. R. B., Dulikravich, G. Pipeline Heating Method Based on Optimal Control and State Estimation. Heat Transfer Engineering, 34, 511-519 (2013). https://doi.org/10.1080/01457632 .2012 .723536

Walker, E., Rayman, S., White, R. E. Comparison of a particle filter and other state estimation methods for prognostics of lithium-ion batteries. Journal of Power Sources, 287, 1-12 (2015). https://doi. org/10.1016/j.jpowsour.2015.04.020

WHO (World Health Organization). Guidelines for drinking-water quality. v.1, Genebra (2008).

Won, W., Lee, K. S. Nonlinear observer with adaptive grid allocation for a fixed-bed adsorption process. Computers \& Chemical Engineering, 46, 69-77 (2012). https://doi.org/10.1016/j. compchemeng.2012.07.001

Wu, K. T., Wu, P. H., Wu, F. C., Jreng, R. L., Juang, R. S., A novel approach to characterizing liquid-phase adsorption on highly porous activated carbons using the Toth equation. Chemical Engineering Journal, 221, 373-381 (2013). https://doi.org/10.1016/j. cej.2013.02.012

Zhao, Z., Huang, B., Liu, F. Constrained particle filtering methods for state estimation of nonlinear process. Aiche Journal, 60, 2072-2082 (2014). https://doi.org/10.1002/aic. 14390

Zhou, S., Wang, Y., Liu, Y., Ji, G. Synchronized Bayesian state estimation in batch processes using a two-dimensional particle filter. Chemical Engineering Research and Design, 125, 9-23 (2017). https://doi.org/10.1016/j.cherd.2017.06.033 